\title{
Sterilization of Seed Carthamus tinctorius (Safflower) Plant and Investigation of the Effectiveness of the Sterilizants
}

\author{
Penbe Merve Korkmaz ${ }^{1}$ (D), Hulya Demir ${ }^{2 *}$ (D), Erdem Tezcan1 ${ }^{(1)}$ \\ ${ }^{1}$ Health Science Faculty, Istanbul Gedik University, Istanbul, Turkey \\ ${ }^{2}$ Health Science Faculty, Yeditepe University, Istanbul, Turkey \\ Email: p.mervekorkmaz@gmail.com, ^hulya.demir@yeditepe.edu.tr, erdem.tezcan@gedik.edu.tr
}

How to cite this paper: Korkmaz, P.M., Demir, H. and Tezcan, E. (2021) Sterilization of Seed Carthamus tinctorius (Safflower) Plant and Investigation of the Effectiveness of the Sterilizants. Agricultural Sciences, 12, 603-619.

https://doi.org/10.4236/as.2021.126039

Received: May 3, 2021

Accepted: June 12, 2021

Published: June 15, 2021

Copyright $\odot 2021$ by author(s) and Scientific Research Publishing Inc. This work is licensed under the Creative Commons Attribution-NonCommercial International License (CC BY-NC 4.0).

http://creativecommons.org/licenses/by-nc/4.0/

\begin{abstract}
Plant tissue culture studies are one of the pretreatments carried out to increase crop yield by preventing germination in plant seeds. In this research, repeated plant tissue culture studies were conducted with sterilizers specific to safflower seed, which will increase production efficiency but do not cause genetic polymorphism and corrosion in endosperm with $3 \mathrm{~N}$ chromosomes. Corrosives were used by dilution, and this did not damage the $3 \mathrm{~N}$ chromosome endosperm, targeting the protein walls of microorganisms on the seed surface without eroding the seed surface, thereby providing biological sterilization. Besides, because it does not contain heavy metals, it did not cause polymorphism, that is, a mutation in the genetic sequence of the seed. Moreover, the environment and the equipment were sterilized with 2 - 3 repetitions, sterilizer treatment, planting, and germination operations were performed in a sterile environment this, in turn, allowed an isolated assessment of the yield of solution $\mathrm{G}$.
\end{abstract}

\section{Keywords}

Safflower Seeds, Sterilization Protocol, Plant Tissue Culture

\section{Introduction}

Safflower or wild saffron (Carthamus tinctorius L.) is a plant belonging to the Asteraceae family, native to the Mediterranean region, cultivated mainly for its orange-red dye (carthamin) found in its flowers and the oil in its seeds [1]. Safflower is an important seed with low levels of saturated fatty acid and high levels of unsaturated fatty acid composition. Two main kinds of fatty acids are ob- 
tained from safflower seeds. These are monounsaturated fatty acids, rich in oleic acid and polyunsaturated fatty acid, rich in linoleic acid [2]. Safflower-derived oleic and linoleic acids are being used as a viscosity and enrichment agent in the food industry and as a supplement in enteral Nutrition formulas [3]. Moreover, it is very common that, safflower oils, which are rich in oleic acids, are being preferred to fry food items such as french fries, chips, and other snack products in the food industry, due to their heat resistance. Safflower (C. Tinctorius) plant, has been shown to have pharmacological properties, such as anti-fibrosis, antidiabetic, antitumor, anti-inflammatory, hepatoprotective, anticoagulant, antihyperlipidemic, and antioxidant activity [1]. Recent market etudes also demonstrate the impact of health-related studies on the health food market for Safflower oil. Approximately $75 \%$ of the linoleic acid-rich safflowers' oil content comes from linoleic acid and is used as an edible oil product such as soft margarine and salad dressing [2]. Safflower oil rich in oleic acid contains less saturated fat and its linoleic acid content is higher than olive oil and may be effective in preventing coronary artery disease [2]. Monounsaturated fatty acids particularly oleic acid can be effective in lowering LDL (Low-Density Lipoprotein) plasma levels without affecting HDL (High-Density Lipoprotein) levels [4]. Despite these various benefits and applications of safflower, it is believed that the production of safflower throughout the world is not sufficient. (Carthamus tinctorius L.) Production, in India, China, USA, Mexico, Turkey all total were 731, 425 tons [5]. This production volume increased to 948,516 tons in 2013 and, 30\% of the total supply has been produced by Russia. Even though Safflower seed cultivation in Turkey largely was intended to be made for cooking oil, since it's recognized that the process and yield of the safflower oil lower than corn and sunflower oil, it was not preferred for this purpose. It is also known that another major part of the production volume was supplied by Mexico and Kazakhstan [6]. Safflower seeds are resistant to environmental conditions such as drought, salt in the soil, and stress caused by these conditions and therefore can be grown easily in several parts of the world [1]. Based on this perspective, it is presumed that safflower seeds may display the ability to adapt to inconvenient climate conditions particularly to global warming, which provokes unsustainable ecological conditions. Furthermore, the ratio of oil in the pulp (husk) varies between $2 \%-20 \%$, and following the oil extraction process, the husk which is rich in plant protein can be used as provender to feed domesticated livestock such as cattle, sheep, horses, chickens and pigs. In this respect, after the oil has been extracted, safflower pulp (husk), a secondary product, is a suitable plant based protein resource for Animal Nutrition [7]. The safflower plant is a multi-purpose plant cultivated globally due to its various functions as safflower seed oil can also be considered as an alternative to petroleum. In order to generate biofuel, safflower seed oil, should be treated with certain chemicals through several stages. Sodium hydroxide $(\mathrm{NaOH})$ transesterification reaction with methyl alcohol results in biodiesel formation. As a result of this, it could be said that the safflower seed oil can be 
utilized as an alternative to petroleum [8]. Thus, nonetheless, its countless health benefits, safflower seed oil may also contribute to meet the global energy demand as a more sustainable source of energy. However, due to lack of appropriate sterilization procedures, the production yields of the safflower seed might not obviate the increased needs of the market. Therefore, in this study a new sterilization protocol, for sterile media and seed, is created to enhance the production yield. Besides, to increase the production yield, it is necessary to remove microorganisms without damaging the endosperm (containing the $3 \mathrm{n}$ chromosome), without causing genetic mutation, without inhibiting the plant nucleus in any way. Since the production efficiency of plants used as hosts by microorganisms decreases, superior genetic material cannot be transferred to the next generation which also impacts the production yield, thus the monetary expenses, extensively. Therefore, it is essential to take the measures needed, establish a treatment protocol, which is not corrosive over seed the husk in order to avoid the cross contamination risk.

Sterilization protocols that are being used, aiming to increase the mass, salutary, and high-quality production of a plant, mostly contain chemicals such as ethanol, chlorhexidine gluconate, bleach (sodium hypochlorite), and mercury chloride [9] [10] [11]. However, whilst existing sterilization protocols for some plant species would not be effective; there haven't any conducted or ongoing research for other plant species. Among plants, it is known that sterilization protocol for safflower seeds has not been developed yet and existing protocols, which do not contain heavy metals, are not sufficient enough to sterilize the seeds. Therefore the purpose of this research is to develop a novel sterilization protocol for the safflower seeds which may contribute to the production yield volume. Based on this hypothesis, an initial sterilization protocol has been developed for safflower tissue culture. In the long run, this research aims to contribute to the scientific literature via publications and patent operations. It has been presumed that the finalized protocols may also have great commercial potential, which is intended to obtain a result, especially from the pharmaceutical industry.

\section{Material and Method}

1) Physical cleaning of the safflower seeds, 2) preparation of chemical formulas and variations, 3) treatment of seeds with chemicals at various doses and at various time intervals (sterilization process), 4) preparation of plant tissue culture petri dishes, 5) sowing of the seeds which have been sterilized in Plant Tissue Culture, 6) incubation of petri dishes in air locked cabinets, 7) evaluation of incubation results (number of contaminated seeds, number of sprouting seeds, number of non-sprouting seeds, etc., 8) finding formulas and protocols that provide sterilization and do not prevent sprouting by making adjustments to chemical formulas and application conditions of sterilizers according to incubation results. The main processes titles are for the synthesis of sterilizers and 
measurement of their antimicrobial activity through plant tissue culture. Plant materials that been used in the study; our target plant is safflower (Carthamus tinctorius L.) seeds and linen for control purposes (Linum usitatissimum L.) seeds. Sterilizing synthesis two consists of 8-hydroxyquinoline (8HQ) derivatives with Plan "A" and persulfuric acid with Plan "B". In addition, mercury chloride, sodium hypochlorite, and ethyl alcohol chemicals, the most commonly used sterilizers in the literature, have been used for control purposes.

\subsection{Synthesis of the Sterilizers}

The primary sterilization protocol performed mainly based on the original formulations [12]. Mixtures containing 1\% - 25\% hydrogen peroxide + $0.1-18 \mathrm{HQ}$ have been prepared as the fundamental formulation. Stabilization of prepared antimicrobial solutions was done with metallic silver nanoparticles. Metallic silver was obtained by the reaction of silver nitrate solutions with reductants such as ascorbic acid and formaldehyde [13]. The vast majority of the antibacterial agents in the formulations, came from hydrogen peroxide. Therefore, the main active ingredient was hydrogen peroxide. The hydrogen peroxide quantities of the samples have been measured immediately after preparation and after undergoing accelerated stability testing, and degradation rates have been calculated. The amount of hydrogen peroxide has been determined by titration of solutions containing $1 \mathrm{~mL} \mathrm{H}_{2} \mathrm{SO}_{4}$ with $\mathrm{KMnO}_{4}$. Accelerated stability tests conducted based on a two week aging procedure at $54^{\circ} \mathrm{C} \pm 2{ }^{\circ} \mathrm{C}$, which is the fastest-yielding temperature first, as stated by the relevant regulations and guidelines [14]. Furthermore when the formulations were not stable under these conditions (the deterioration rate in the active substance is greater than $10 \%$ ), the aging procedures have been repeated for four weeks at $50^{\circ} \mathrm{C} \pm 2^{\circ} \mathrm{C}$ or six weeks at $45^{\circ} \mathrm{C} \pm 2^{\circ} \mathrm{C}$ instead of two weeks at $54^{\circ} \mathrm{C} \pm 2^{\circ} \mathrm{C}$.

\subsection{Synthesis of Persulfuric Acid-Based Sterilizers}

The production of persulfuric acid has been described by the executive in his doctoral work [12] and in various literature sources [15] as stated, has been carried out by adding concentrated (50\%) hydrogen peroxide on top of concentrated sulfuric acid in ice bath-soaked and mixed with magnetic stirrer with hot plate. The synthesis of persulfuric acid has been carried out immediately prior to use, in order to maintain the stability of the newly synthesized persulfuric acid which was being used continuously.

\subsection{Media Preparation}

The components specified, have been dissolved in deionized water so that the final volume is $1000 \mathrm{~mL}$. Medium containing Agar heated at the same time while mixing Agar and the Agar completely dissolved. Then the media sterilized by autoclaving (Table 1). 
Table 1. Prescriptions of bacterial culture media (g/L) [16] [17].

\begin{tabular}{cccccc}
\hline Compounds & $\begin{array}{c}\text { Luria Agar } \\
\text { (LA) }\end{array}$ & $\begin{array}{c}\text { Luria Broth } \\
\text { (LB) }\end{array}$ & $\begin{array}{c}\text { Tryptic Soy } \\
\text { Agar (TSA) }\end{array}$ & $\begin{array}{c}\text { Tryptic Soy } \\
\text { Broth (TSB) }\end{array}$ & $\begin{array}{c}\text { Plate Count } \\
\text { Agar } \\
\text { (PCA) }\end{array}$ \\
\hline Bacto tryptone & 10.0 & 10.0 & 15.0 & 15.0 & 5.0 \\
Bacto soytone & - & - & 5.0 & 5.0 & - \\
$\mathrm{NaCl}$ & 10.0 & 10.0 & 5.0 & 5.0 & - \\
Yeast extract & 5.0 & 5.0 & - & - & 2.5 \\
Dextrose & - & - & 2.5 & 2.5 & 1 \\
$\mathrm{~K}_{2} \mathrm{HPO}_{4}$ & - & - & 2.5 & 2.5 & - \\
Agar & 15 & - & 15 & - & 7.5 \\
\hline
\end{tabular}

\subsection{Preparation of the Hard Water}

Solution A: $19.84 \mathrm{~g} \mathrm{MgCl}_{2}$ and $46.24 \mathrm{~g} \mathrm{CaCl}_{2}$ are dissolved in deionized water and after the volume is completed to $1000 \mathrm{ml}$ with deionized water, the injector tip of $0.2 \mu \mathrm{L}$ sterilized with the filter. It is stored in the refrigerator with its mouth closed. Solution B: $35.02 \mathrm{~g} \mathrm{NaHCO}_{3}$ dissolved in deionized water and its volume is completed to $1000 \mathrm{~mL}$ with deionized water, then $0.2 \mu \mathrm{L}$ injector end sterilized by the filter. It was stored in $+4^{\circ} \mathrm{C}$. Hard water: $600-700 \mathrm{~mL}$ deionized water added to the $1000 \mathrm{~mL}$ beaker. Then, $6.0 \mathrm{~mL}$ solution A and $8.0 \mathrm{~mL}$ solution $\mathrm{B}$ added and the $\mathrm{pH}$ measurement done. Since, the $\mathrm{pH}$ should be in the range of $7.0 \pm 0.2$ a pH adjustment made with $1 \mathrm{M} \mathrm{NaOH}$ or $1 \mathrm{M} \mathrm{HCl}$. Then, the solution was taken into a $1000 \mathrm{~mL}$ volumetric flaks and its volume was completed to $1000 \mathrm{~mL}$ with deionized water [16] [17]. $1.0 \mathrm{~g}$ bacto tryptone and $8.5 \mathrm{~g}$ $\mathrm{NaCl}$ were dissolved in deionized water and the volume is completed to $1000 \mathrm{~mL}$ with deionized water and then the injector end of $0.2 \mu \mathrm{L}$ is sterilized with the filter. It will be stored in $+4^{\circ} \mathrm{C}$.

\subsection{Preparation of Neutralization}

After the volume of $3 \mathrm{~g}$ sodium thiosulfate, $30 \mathrm{~g}$ polysorbate 80 , and $3 \mathrm{~g}$ lecithin is dissolved in water and completed to $1000 \mathrm{~mL}$ with deionized water, the injector tip of $0.2 \mu \mathrm{L}$ is sterilized with the filter. It is stored in the refrigerator with its mouth close [16] [17].

\subsection{Preparation of Bacterial Cultures}

First, pre-cultures of bacterial strains stored at $80^{\circ} \mathrm{C}$ prepared. For the planting, from bacterial strains into $10 \mathrm{~mL}$ liquid media and incubated for 16 hours at $37^{\circ} \mathrm{C}$ in a churning incubator. Liquid media used, E. coli, B.subtilis, and Luria Broth for $P$. aeruginosa, $S$. aereus have been used. Then the solutions incubated at $37^{\circ} \mathrm{C}$, with $100 \mu \mathrm{L}$ of the pre-cultures planted in $50 \mathrm{~mL}$ of fresh liquid media.

Their turbidities measured in the McFarland device by taking occasional samples from the culture. Until the McFarland scale is 1 (this value is equivalent to 
approximately $300 \times 10^{6}=3 \times 10^{8} \mathrm{CFU}$ for E. coli) incubation continued [18]. In case of contamination during preparation of planktonic form bacteria, experiments re-duplicated via sterilized culture.

\subsection{Determination of Antibacterial Activity}

\subsubsection{Zone Diameter Measurement Method}

The method for measurement of zone diameters adapted. Plate Count Agar (PCA) or Tryptic Soy Agar (TSA) media prepared according to the type of bacterial cultures (Table 1). As soft agar media cools, just before full solidification, $100 \mu \mathrm{L}$ (approximately $3 \times 10^{7} \mathrm{CFU}$ ) bacterial culture added to the $15 \mathrm{~mL}$ solid media and mixed homogenously and then poured into the petri dish. Soft Agar containing bacteria (containing $7.5 \mathrm{~g} / \mathrm{L}$ agar) media solidified and cooled to room temperature, $10 \mu \mathrm{L}$ of the chemical formulation tested on the agar media added and the petri dish will be incubated at $37^{\circ} \mathrm{C}$ for 16 hours. The diameter of the inhibition zone measured and recorded for each formulation and dilution rate [19].

\subsubsection{Determination of Minimal İnhibitory Concentration (MIC) and Minimal Bactericidal Concentration (MBC)}

For the determination of Minimal inhibitory concentration (MIC) and minimal bactericidal concentration (MBC), the formulation was adapted. For this, by diluting 2 layers at a time, the formulations are 2-1,2-2, etc. 2-N was prepared as well as various dilutions. Then, $10 \mu \mathrm{L}$ was added to each well from a stock of replicated bacteria until the McFarland scale is 1 . Next, the 96 -well plaque was incubated 24 hours at $37^{\circ} \mathrm{C}$. The lowest concentration value that suppresses the growth of microorganisms recorded as MIC. For the determination of MBC, 100 samples taken from wells without growth (without blur) planted in solid media and incubated for 24 hours at $37^{\circ} \mathrm{C}$. The lowest concentration without growth was recorded as MBC. At least 2 parallel experiments were conducted for the determination of MIC and MBC [19].

\subsubsection{Standard Test Method for Antibacterial Activity}

The samples showing the inhibition zone in the zone diameter measurement method are more comprehensive than the standard method set by the Ministry of Health which subjected to antibacterial activity testing using TS EN 13727+A2 [17].

\subsection{Plant Tissue Culture Experiments}

Plant tissue culture processes generally be based on the adaptation of the work with the mercury chloride sterilizer conducted by Orlikowska and Dyer (1993) through the use of self-produced sterilizers [20]. The safflower seeds used in the study group and the flax seeds to be used in the control group first cleaned in the existence of the physical contamination and then washed with sterile distilled water in the laminar cabinet. After this process, the seeds treated at room tem- 
perature for certain periods ( $3 \mathrm{~min}, 5 \mathrm{~min}, 10 \mathrm{~min}, 15 \mathrm{~min}, 30 \mathrm{~min}, 1$ hour) in sterilizing solution using sterile pliers. In case the sterilizers are ineffective, in some experiments, ultrasonic baths used to increase the effectiveness of the sterilizer by allowing it to be absorbed into the seed pores. After the sterilizing treatment, the seeds washed repeatedly with sterile water and the sterilization step terminated. Each sterilizer and its protocol tested with at least 10 seed, and at the end of the process at least one of the seeds observed to be irritated on its surface using a stereomicroscope.

Murashige and Skoog medium (abbreviated MS Agar) has been used as the media for the seed cultivation which is a non-selective medium for the cultivation of fungi and the decomposition of the yeast of the genus Candida based on their morphological characteristics [21]. For the planting of safflower seeds, the site of MS Agar media was used. For 1 liter of agar, 8 grams of agar, 30 grams of glucose, 2.15 grams of MS media place were added sterile and mixed in a 1-liter transparent autoclave bottle. The mixture is then mixed with the help of magnetic fish until it becomes clear in a heated magnetic mixer. Then the MS agar media was sterilized by autoclave. Sterilization runs in such a way that, depending upon the question to be sterilized, a vacuum is shaped at slightest once for at slightest a brief time earlier to the genuine sterilization in which hot steam beneath a weight of around two to four bar and at a temperature of $120^{\circ} \mathrm{C}-140^{\circ} \mathrm{C}$ is display within the sterilization chamber for generally one to 30 minutes [22].

The agar media place mixture is prepared with sterile water and autoclaved with materials such as pliers, beakers, to be used for the experiment. The agar media, which was then left to cool at room temperature, was sterilized with the help of $70 \%$ ethyl alcohol solution and microbiological cabinet ultraviolet ray. In the microbiological cabin, the agar media was sterilized and poured into petri dishes $30 \mathrm{~mL}$ 's per petri dish, with the help of micro pipette. In addition, MS agar media, which was poured into the petri dish left to cool down, in the microbiological cabin and sterilized a second time under ultraviolet radiation in the cabin to prevent the possibility of contamination.

\section{Results}

\section{Sterilization and the Planting of the Safflower Seeds}

Acid or sterilizing solutions were mixed with distilled water in different proportions, resulting in acid solution. In primary experiments, two volumes of sulfuric acid and one volume of hydrogen peroxide were mixed with a dropper, and the acid mixtures were mixed with distilled water to obtain $25 \mathrm{~mL}$ of solutions in the santrifuge tube. Sulfuric acid $\left(\mathrm{H}_{2} \mathrm{SO}_{4}\right)$, water, and hydrogen peroxide $\left(\mathrm{H}_{2} \mathrm{O}_{2}\right)$, mixture also known as piranha solution (persulfuric acid), is being utilized to clean organic residues off substrates [23]. Since the mixture could be a solid oxidizing agent, it expels most natural matter, and hydroxylates most surfaces (include Gracious groups), making them exceedingly hydrophilic (water-compatible). 
Four different solutions were prepared in the precursor experiment, and named after letters A, B, C and D. 1) For the production of solution A; $1 \mathrm{~mL}$ acid solution is mixed with $24 \mathrm{~mL}$ of distilled water; 2) for the production of solution $\mathrm{B}$, $2.5 \mathrm{~mL}$ of the acid solution is mixed with $22.5 \mathrm{~mL}$ of distilled water; 3 ) for the production of $\mathrm{C}$ solution; $5 \mathrm{~mL}$ of the acid solution is mixed with $20 \mathrm{~mL}$ of distilled water; 4) for the production of solution $\mathrm{D}, 10 \mathrm{~mL}$ of the acid solution is mixed with $15 \mathrm{~mL}$ of distilled water. Safflower seeds were added to each acid solution and kept for certain periods. The seeds were removed one by one with the help of collets, removed from the centrifuge tube, and soaked in $70 \%$ ethanol solution. For each solution, two Petri dishes, five seeds were planted in a microbiological cabin. Two samples were obtained from each solution group and samples were paraffined in the microbiological cabinet and taken to the air conditioning cabinet.

Control experiments (seeds that were sown directly without any sterilization process and sterile petries that did not planted) yielded results as expected. No seed-free control was contaminated after incubation, while no sterilized control was contaminated as a result of incubation (Figure 1(a) and Figure 1(b)).

Only persulfuric acid was applied in samples of 1.0, 2.5 and $5.0 \mathrm{~mL}$ persulfuric acid applications, all seeds were exposed but almost all of them had at least one contamination.

The application of $10 \mathrm{~mL}$ persulfuric acid largely prevented the seed from flowering but did not reset it, although it reduced the contamination. Therefore, ethanol application processes were initiated in the following processes. MS agar preparations and the sterilization protocol were repeated at the beginning of each experiment. According to the results obtained, in ongoing experiments, stages such as solution concentrations, application times, pre-treatment with ethanol, and duration were reviewed and various modifications were in the application. The efficiency of the applications made as a result of the precursor experiments was reviewed, and secondary and tertiary experiments were intervened in accordance with these results (Table 2).

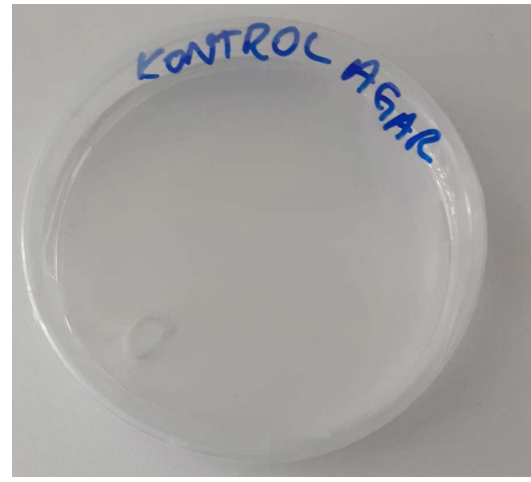

(a)

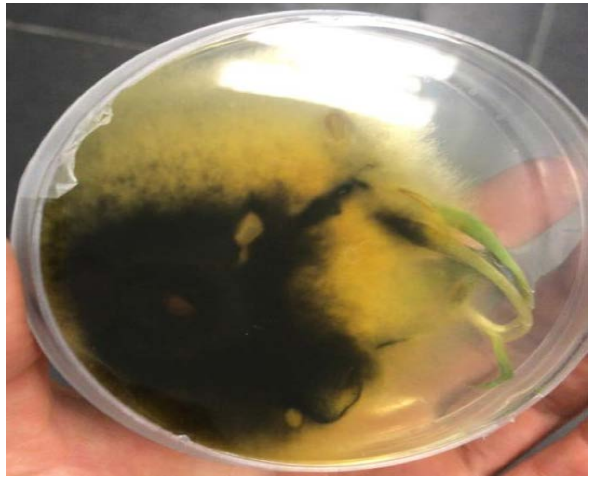

(b)

Figure 1. (a) Post-incubation status of Seed-free control; (b) post-incubation statusof non-sterilized control sample. 
Table 2. Sterilization trials of the safflower seeds (secondary experiments).

\begin{tabular}{cccccc}
\hline Compounds & $\begin{array}{c}\text { Luria Agar } \\
\text { (LA) }\end{array}$ & $\begin{array}{c}\text { Luria Broth } \\
\text { (LB) }\end{array}$ & $\begin{array}{c}\text { Tryptic Soy } \\
\text { Agar (TSA) }\end{array}$ & $\begin{array}{c}\text { Tryptic Soy } \\
\text { Broth (TSB) }\end{array}$ & $\begin{array}{c}\text { Plate Count } \\
\text { Agar } \\
\text { (PCA) }\end{array}$ \\
\hline Bacto tryptone & 10.0 & 10.0 & 15.0 & 15.0 & 5.0 \\
Bacto soytone & - & - & 5.0 & 5.0 & - \\
$\mathrm{NaCl}$ & 10.0 & 10.0 & 5.0 & 5.0 & - \\
Yeast extract & 5.0 & 5.0 & - & - & 2.5 \\
Dextrose & - & - & 2.5 & 2.5 & 1 \\
$\mathrm{~K}_{2} \mathrm{HPO}_{4}$ & - & - & 2.5 & 2.5 & - \\
Agar & 15 & - & 15 & - & 7.5 \\
\hline
\end{tabular}

A solution containing $1 \mathrm{~mL}$ of persulfuric acid was contaminated in samples treated first with ethanol and then with persulfuric acid; samples containing 2.5, 5 and $10 \mathrm{~mL}$ of persulfuric acid were not contaminated but did not seed (Figure 2).

These experiments are not ideal as there is no seed opening. Both before and after persulfuric acid ethanol samples were completely sterilized, but no seed opening (Figure 3).

In the study where didecyldimethylammoniumchloride (DDAC) was applied for $10 \mathrm{~min}$ alone, contamination could not be prevented but Seed opening could not be provided (Figure 4).

All samples containing DDAC and persulfuric acid were completely sterilized but no seed opening was provided (Figure 5).

The opening of the seeds was provided for the application of persulfuric acid in $1,2.5,5 \mathrm{~mL}$, and most of the seeds were obtained sterile. However, ethanol and DDAC chemicals in these samples are also contaminated due to some seeds 2 or 3. It was applied as a process step but no success was achieved in seed opening. Therefore, the next steps have been followeds:

treatment with $70 \%$ ethanol for short periods after application of persulfuric acid; prolongation of the application of persulfuric acid alone; providing processing of chemicals into seeds by using ultrasonic bath in applications.

The next phases; safflower seeds were kept for $10 \mathrm{~min}$ in the solutions prescribed and applied in Table 3 and were sterilized with 1 - 3-stage processes and soaked in sterile media in petri dishes after the study. No sterilization process is done and the sterile MS agar media in which no seeds are dipped were used as a control. After that, the petries containing seeds were wrapped with parafilm and kept in room conditions for one week in light, germination and contamination data were recorded (Table 4).

Seed-free control has never been contaminated after incubation. Only persulfuric acid was applied in samples of 1, 2.5 and $5 \mathrm{~mL}$ persulfuric acid applications, all seeds were exposed but almost all of them had at least one contamination. The application of $10 \mathrm{~mL}$ persulfuric acid largely prevented the seed from flowering 

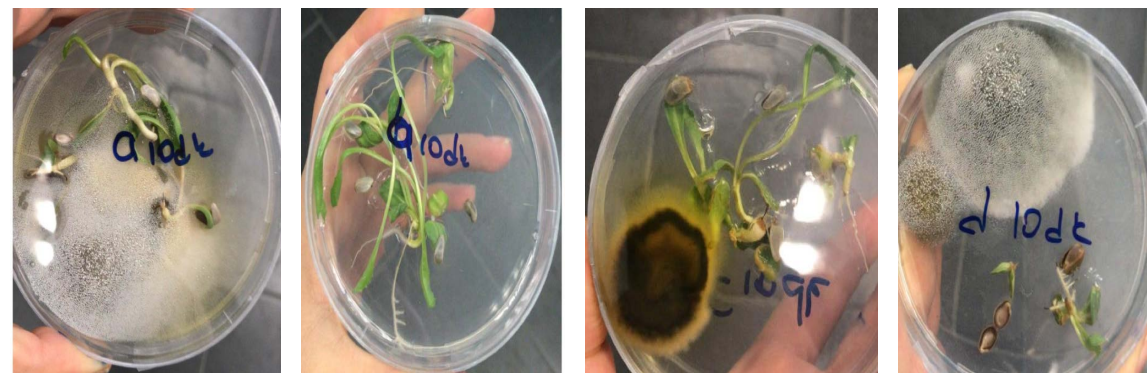

Figure 2. Persulfuric acid only applied samples.
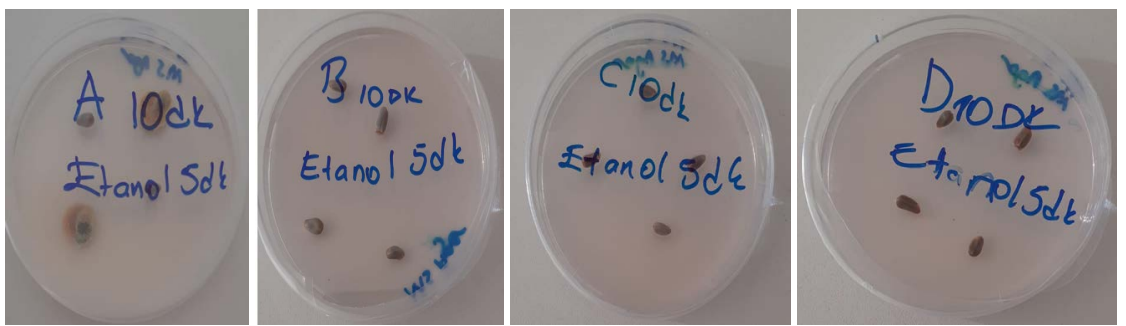

Figure 3. Samples treated first with ethanol and then persulfuric acid.

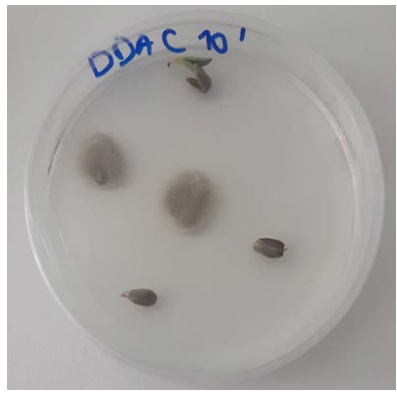

Figure 4. DDAC-only implementation.

Table 3. Sterilization trials of safflower seeds (Tertiary experiments).

\begin{tabular}{cccc}
\hline & $\begin{array}{c}\text { 70\% ethanol } \\
\text { pre-treatment } \\
(5 \text { min treatment })\end{array}$ & $\begin{array}{c}\text { Amount of persulfuric acid } \\
\text { (completed to } 25 \text { ml with deionized water, } \\
10 \text { min treatment) } \\
2 \mathrm{~V}\end{array}$ & $\begin{array}{c}70 \% \text { ethanol } \\
\text { final treatment }\end{array}$ \\
\hline A & - & $1 \mathrm{~mL}$ & + \\
B & - & $2.5 \mathrm{~mL}$ & + \\
C & - & $5 \mathrm{~mL}$ & + \\
$\mathrm{D}$ & - & $10 \mathrm{~mL}$ & + \\
$\mathrm{A}_{\text {eth }}$ & + & $1 \mathrm{~mL}$ & + \\
$\mathrm{B}_{\text {eth }}$ & + & $2.5 \mathrm{~mL}$ & + \\
$\mathrm{C}_{\text {eth }}$ & + & $5 \mathrm{~mL}$ & + \\
$\mathrm{D}_{\text {eth }}$ & + & $10 \mathrm{~mL}$ & + \\
\hline
\end{tabular}

but did not reset it despite reducing conta mination. Therefore, ethanol application processes were initiated in the following processes. 


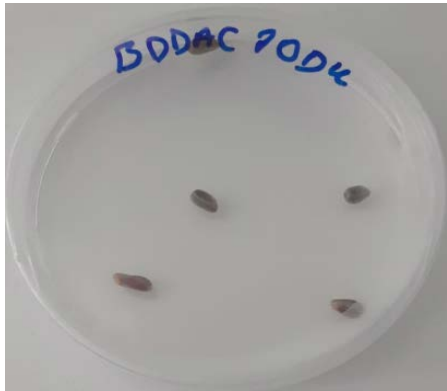

Figure 5. Sample sterilized with $25 \mathrm{~mL}$ aqueous solution containing $2.5 \mathrm{~mL}$ persulfuric acid +2.5 g DDAC.

Table 4. Sterilization trials of safflower seeds with an additional G solution.

\begin{tabular}{ccccc}
\hline & $\begin{array}{c}70 \% \text { ethanol } \\
\text { pre-treatment } \\
(5 \text { min treatment) }\end{array}$ & $\begin{array}{c}\text { Amount of persulfuric acid (completed } \\
\text { with deionized water to } 25 \mathrm{~mL}) \\
2 \mathrm{~V} \mathrm{H}_{2} \mathrm{O}_{2}-1 \mathrm{~V} \mathrm{H}_{2} \mathrm{SO}_{4}\end{array}$ & Time & $\begin{array}{c}\text { 70\% ethanol } \\
\text { final } \\
\text { treatment }\end{array}$ \\
\hline $\mathrm{G}$ & - & $2.5 \mathrm{~mL}$ & $10 \mathrm{mins}$ & +
\end{tabular}

Only A, B and C solutions exposed to persulfiric acid germinated, but even if some of the samples applied both before and after ethanol were completely sterilized, seed growth was inhibited and seed opening was not. As a result of the success of the experiments with solution $G$, the same experiments were repeated in the following months to ensure the accuracy of the result (Figure 6 and Figure 7).

As a result of the success of the experiments with solution $G$, the same experiments were repeated in the following months to ensure the accuracy of the result. Subsequent Studies with G solution; The opening of the seeds was provided for the application of persulfuric acid in 1,2.5, $5 \mathrm{~mL}$, and most of the seeds were obtained sterile. However, in these samples, a new persulfuric solution was prepared at concentrations of ethanol and $2 \mathrm{~V} \mathrm{H}_{2} \mathrm{O}_{2}-1 \mathrm{~V} \mathrm{H}_{2} \mathrm{SO}_{4}$ due to the contamination of some seeds. Experiments showed that $100 \%$ success was achieved in seeds treated in $\mathrm{G}$ solution for $10 \mathrm{~min}$ at the end of the first and second repeats. In other words, $100 \%$ sterilization was provided in all seeds and germination was seen.

In the later stages of the experiment, the reliability of solution $G$ tested and trials on solutions B and C continued. Solutions B and C tested at exposure times of $10-15$ and $20 \mathrm{~min}$, with $5 \mathrm{~min}$ of ethanol pre-intervention held steady. G solution also tested with 10 and 15 min ethanol pre-intervention and $5 \mathrm{~min}$ $70 \%$ ethanol pre-intervention. For all solutions, $70 \%$ of ethanol treated last before planting (Table 5).

The most efficient result in $\mathrm{G}$ solution processes ( 0 contaminations, $100 \%$ germination) was taken if the seeds were pre-and final intervention with $70 \%$ ethanol and kept in G solution for 10 minutes. Under these conditions, it has been observed that complete success has been achieved with Formula G (Figure 8). 


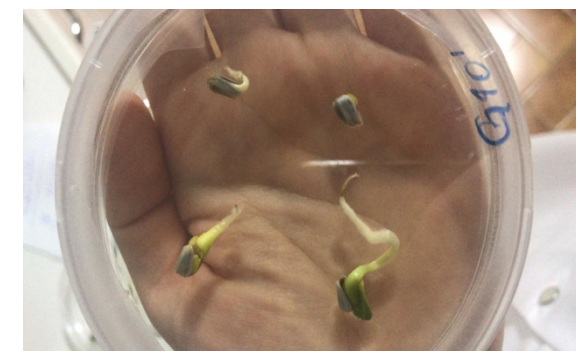

Figure 6. Samples treated with G solution (1 week after the experiment).

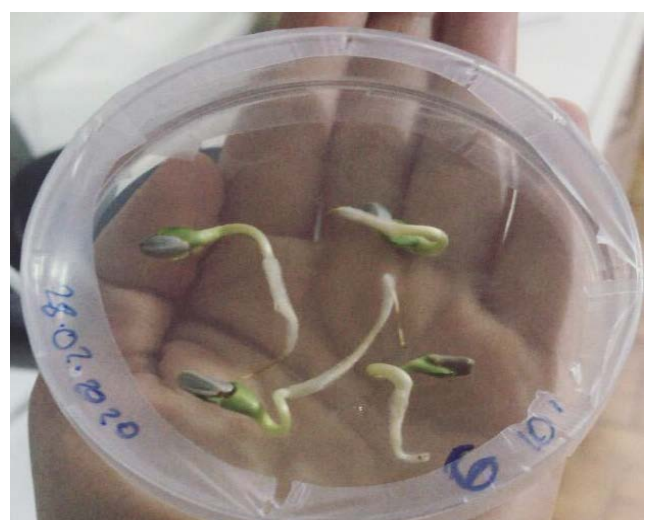

Figure 7. Samples treated with G solution (2 weeks from the experiment).

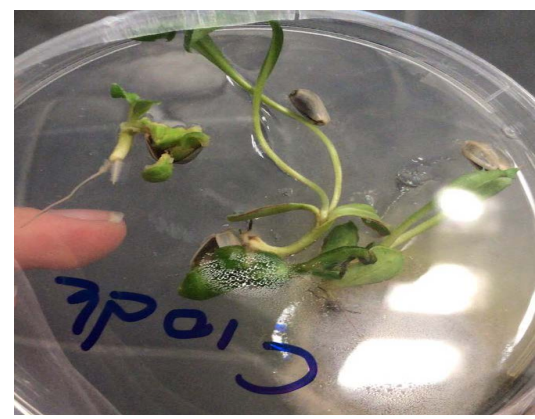

Figure 8. Seeds treated with the G formulation for $10 \mathrm{~min}$.

Table 5. Subsequent studies with G solution.

\begin{tabular}{cccc}
\hline $\begin{array}{c}\text { G solution } \\
\text { mL }\end{array}$ & $\begin{array}{c}\text { The Amount of } \\
\text { the Sterile Water, } \\
\mathrm{mL}\end{array}$ & $\begin{array}{c}\text { Period } \\
\text { (mins) }\end{array}$ & $\begin{array}{c}\text { Results } \\
\text { Contamination/Germination/ } \\
\text { Dormancy (Over 5 Seeds Each) }\end{array}$ \\
\hline $2 \mathrm{~V} \mathrm{H}_{2} \mathrm{O}_{2} 1 \mathrm{~V} \mathrm{H}_{2} \mathrm{SO}_{4}$ & $22.5 \mathrm{~mL}$ & 3 & $0 / 0 / 5$ \\
$2 \mathrm{~V} \mathrm{H}_{2} \mathrm{O}_{2} 1 \mathrm{~V} \mathrm{H}_{2} \mathrm{SO}_{4}$ & $22.5 \mathrm{~mL}$ & 3 & $0 / 1 / 4$ \\
$2 \mathrm{~V} \mathrm{H}_{2} \mathrm{O}_{2} 1 \mathrm{~V} \mathrm{H}_{2} \mathrm{SO}_{4}$ & $22.5 \mathrm{~mL}$ & 5 & $2 / 2 / 1$ \\
$2 \mathrm{~V} \mathrm{H}_{2} \mathrm{O}_{2} 1 \mathrm{~V} \mathrm{H}_{2} \mathrm{SO}_{4}$ & $22.5 \mathrm{~mL}$ & 5 & $2 / 2 / 1$ \\
$2 \mathrm{~V} \mathrm{H}_{2} \mathrm{O}_{2} 1 \mathrm{~V} \mathrm{H}_{2} \mathrm{SO}_{4}$ & $22.5 \mathrm{~mL}$ & 10 & $0 / 5 / 0$ \\
$2 \mathrm{~V} \mathrm{H}_{2} \mathrm{O}_{2} 1 \mathrm{~V} \mathrm{H}_{2} \mathrm{SO}_{4}$ & $22.5 \mathrm{~mL}$ & 10 & $0 / 5 / 0$ \\
$2 \mathrm{~V} \mathrm{H}_{2} \mathrm{O}_{2} 1 \mathrm{~V} \mathrm{H}_{2} \mathrm{SO}_{4}$ & $22.5 \mathrm{~mL}$ & 15 & $1 / 0 / 5$ \\
$2 \mathrm{~V} \mathrm{H}_{2} \mathrm{O}_{2} 1 \mathrm{~V} \mathrm{H}_{2} \mathrm{SO}_{4}$ & $22.5 \mathrm{~mL}$ & 15 & $0 / 1 / 4$
\end{tabular}


However, experiments continued with oxone, one of the commonly used sterilizers within easy reach in the industry. Given the preparation of Formula $G$ and application processes it has been presumed that oxone tobe more accessible compared to $\mathrm{G}$ formulation.

Subsequent Studies with Oxone Solution; After solution G implementations, sterilization esperiments were continued with potassium peroxymonosulfate $\left(\mathrm{KHSO}_{5}\right)$, which is also known as Oxone industrially. At least two repetitions of each experiment were performed. Even if success was achieved with $G$ solution during precursor experiments, stability was found to depend on the external conditions of the laboratory environment. Agar preparation, pre-and final intervention with $70 \%$ ethanol and equipment sterilization steps repeated for five seeds each as mentioned throughout the experiments. Results of repeated experiments with Oxone are shown in Table 6 below.

As a result of experiments with Oxone, the same process steps were repeated over the course of two weeks (Figure 9).
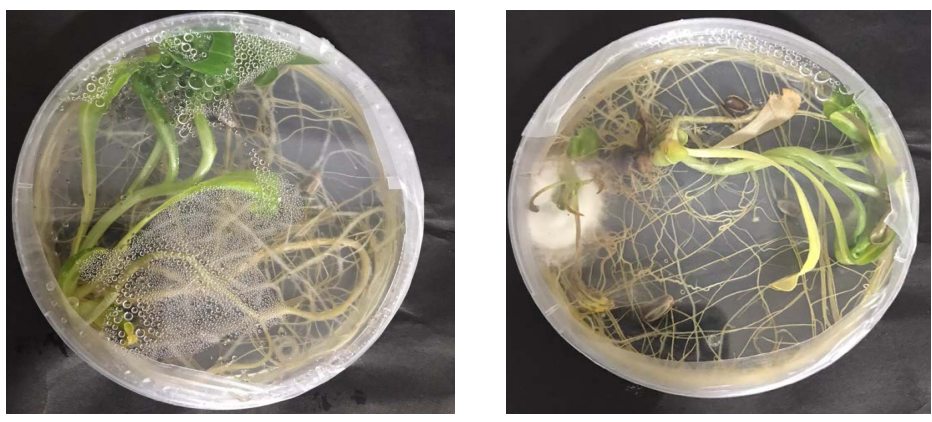

Figure 9. Safflower seeds treated with Oxone for $10 \mathrm{~min}$ (\% success).

Table 6. Subsequent studies with Oxone solution.

\begin{tabular}{cccc}
\hline $\begin{array}{c}\text { Oxone Solution } \\
\text { Concentrations, } \\
\text { grams }\end{array}$ & $\begin{array}{c}\text { The Amount of } \\
\text { the Sterile Water, } \\
\mathrm{mL}\end{array}$ & $\begin{array}{c}\text { Period } \\
\text { (mins) }\end{array}$ & $\begin{array}{c}\text { Results } \\
\text { Contamination/Germination/ } \\
\text { Dormancy (Over 5 Seeds Each) }\end{array}$ \\
\hline 2.5 grams of $\mathrm{KHSO}_{5}$ & $22.5 \mathrm{~mL}$ & 3 & $3 / 1 / 1$ \\
2.5 grams of $\mathrm{KHSO}_{5}$ & $22.5 \mathrm{~mL}$ & 3 & $2 / 0 / 4$ \\
2.5 grams of $\mathrm{KHSO}_{5}$ & $22.5 \mathrm{~mL}$ & 5 & $2 / 1 / 2$ \\
2.5 grams of $\mathrm{KHSO}_{5}$ & $22.5 \mathrm{~mL}$ & 5 & $2 / 2 / 1$ \\
2.5 grams of $\mathrm{KHSO}_{5}$ & $22.5 \mathrm{~mL}$ & 10 & $0 / 2 / 3$ \\
2.5 grams of $\mathrm{KHSO}_{5}$ & $22.5 \mathrm{~mL}$ & 10 & $1 / 3 / 1$ \\
2.5 grams of $\mathrm{KHSO}_{5}$ & $22.5 \mathrm{~mL}$ & 10 & $0 / 5 / 0$ \\
2.5 grams of $\mathrm{KHSO}_{5}$ & $22.5 \mathrm{~mL}$ & 15 & $0 / 0 / 5$ \\
2.5 grams of $\mathrm{KHSO}_{5}$ & $22.5 \mathrm{~mL}$ & 15 & $0 / 0 / 5$ \\
2.5 grams of $\mathrm{KHSO}_{5}$ & $22.5 \mathrm{~mL}$ & 15 & $0 / 0 / 4$ \\
2.5 grams of $\mathrm{KHSO}_{5}$ & $22.5 \mathrm{~mL}$ & 30 & $0 / 1 / 4$ \\
2.5 grams of $\mathrm{KHSO}_{5}$ & $22.5 \mathrm{~mL}$ & 30 & $1 / 2 / 2$ \\
\hline & & & \\
\hline
\end{tabular}




\section{Discussion}

Plant tissue culture utilizations that had been made in this study aimed to cover and incorporate all angles of the in vitro culture of plant cells for the safflower seeds (Carthamus tinctorius L.) which have never been studied on thoroughly. Such tissue societies have been utilized in five wide zones of inquiring about and application [24]. These are pondering on cell behavior, plant modification and improvement, generation of pathogen-free plants and germplasm capacity, clonal engendering, and auxiliary product formation. These three last-mentioned more connected zones are being pursued widely. Be that as it may, in all of the over ranges great advance is being made with an assortment of plant species [25], with micropropagation being the foremost progressed commercial action [26].

It is known to be critical to estimate how plant seeds may germinate in the field using the lab tests in order to predict the yield efficiency. Therefore, laboratory experiments were conducted to determine safflower (Carthamus tinctorius $L$.) seed germination potential in different sterilization solutions. Throughout the research, microbiological and plant tissue culture experiments have been implemented by the observable efficacy of each solution. The vigor tests including plant tissue culture, seed germination, microbiological, and seedling growth rate were performed. The research work consisted of multiple-step experiments such as seed sterilization and the germination/seedling growth. It has been reported that safflower seeds that have not been sterilized properly are often severely infected by various fungi, in contrast to seeds sterilized in a controlled environment. In this way, it may be a specific challenge when intensely sullied seeds are studied in vitro, especially when the seed supply and the sterilization protocol is restricted. Moreover the utilization of a common surface sterilization agent, such as DDAC is not effective and results in poor germination. Germination inhibition or dormancy has been observed with extremely corrosive chemical agents, pesticides, and other sterilizing agents which was not the preferable outcome. Even though DDAC as a sterilizing agent that is being used in the food and medical industries, it has been stated as a highly corrosive chemical that causes skin irritation in humans at high concentrations [27]. On the other hand, diluted formulations created with DDAC have been presented to demonstrate low efficacy in terms of sterilizing activity. It is suggested that improvement studies conducted to prevent germination inhibition are unlikely to succeed while increasing the seed sterilization ability of such chemicals with industrial accessibility. A large number of pre-processing steps make utilization more challanging in terms of industrial and agricultural usage [28]. In addition, the problem of not optimizing germination quality and yield during the plantation process is one of the obstacles in terms of mass production and industrialization of the main and sub-products such as the safflower oil which known to possess phytotherapeutic properties [27].

Other external and environmental variables such as salinity, the mineral com- 
bination of the soil, and humidity have the lacking capacity as perilous natural constraining components for plant productivity. Moreover, when conditions such as germination rate, foliation rate, weight gain after germination were evaluated, the most successful results were obtained with the newly synthesized G solution and the $10 \%$ Oxone solution.

\section{Conclusions}

Plant tissue culture studies are one of the pretreatments carried out to increase crop yield by preventing germination in plant seeds. Although there is no general protocol for plant sterilization, sterilization protocols vary according to the botanical and taxonomic characteristics of each plant, the adaptation and genetic characteristics it provides to the region where it grows. In this study, a new sterilization protocol, for sterile media and seed, is created to enhance the production yield. Besides, to increase the production yield, it is necessary to remove microorganisms without damaging the endosperm, without causing genetic mutation, without inhibiting the plant nucleus in any way. Since the production efficiency of plants used as hosts by microorganisms decreases, superior genetic material cannot be transferred to the next generation which also impacts the production yield, thus the monetary expenses, extensively. Therefore, it is essential to take the measures needed, establish a treatment protocol, which is not corrosive over seed the husk in order to avoid the cross contamination risk.

A current sterilization protocol is developed to increase the production of safflower seeds. While success is achieved in the sterilization processes by using unique solution $\mathrm{G}$, which is synthesized within the scope of this study, and Potassium Peroxymonosulphate solution, having the commercial name Oxone, dormancy is not observed, and germination has occurred without any wastage.

\section{Acknowledgements}

This research was supported by a grant from the Coordinator of Scientific Research Projects of the Istanbul Gedik University.

\section{Conflicts of Interest}

The authors declare no conflicts of interest regarding the publication of this paper.

\section{References}

[1] Gautam, S., Bhagyawant, S.S. and Srivastava, N. (2014) Detailed Study on Therapeutic Properties, Uses and Pharmacological Applications of Safflower (Carthamus tinctorius L.). International Journal of Ayurveda and Pharma Research, 2, 5-16.

[2] Agricultural Marketing Resource Center (2017) Safflower. https://www.agmrc.org/commodities-products/grains-oilseeds/safflower

[3] Sonneville, K. (2013) Manual of Pediatric Nutrition. 5th Edition, Kindle Edition, People's Medical Publishing House. 
[4] Cox, C., Sutherland, W., Mann, J., De Jong, S., Chisholm, A. and Skeaff, M. (1998) Effects of Dietary Coconut Oil, Butter and Safflower Oil on Plasma Lipids, Lipoproteins and Lathosterol Levels. European Journal of Clinical Nutrition, 52, 650-654. https://doi.org/10.1038/sj.ejcn.1600621

[5] Han, X., Cheng, L., Zhang, R. and Bi, J. (2009). Extraction of Safflower Seed Oil by Supercritical $\mathrm{CO}_{2}$. Journal of Food Engineering, 92, 370-376.

https://doi.org/10.1016/j.jfoodeng.2008.12.002

[6] Food and Agriculture Organization of the United Nations. World Production of Safflower Seeds in 2016. http://www.fao.org/faostat/en/\#search/safflower

[7] United Nations Food and Agriculture Organization, Statistics Division (FAOSTAT) (2017) The State of Food Security and Nutrition in the Word 2020.

[8] Ilkılıç, C., Aydın, S., Behcet, R. and Aydin, H. (2011) Biodiesel from Safflower Oil and Its Application in a Diesel Engine. Fuel Processing Technology, 92, 356-362. https://doi.org/10.1016/j.fuproc.2010.09.028

[9] Yakar, Y., Tekel, I.Y., Duru, M., Danahaliloglu, H. and Bucak, S. (2014) The Effect of Feeding with Safflower Seed Added Mixed Feed on the Fatty Acid Composition in Eggs. Ziraat Fakultesi Dergisi, Mustafa Kemal University, 19, 44-55.

[10] Ahmad, M., Nangyal, H., Imran, M. and Ullah, F. (2016) Optimization of Protocol for Surface Sterilization and Callus Induction for Three Rice Varieties. American-Eurasian Journal of Agricultural \& Environmental Sciences, 16, 357-361.

[11] Bakhsh, A., Anayol, E., Sancak, C. and Ozcan, S. (2016) An Efficient and Cost Effective Sterilizing Method with Least Microbial Contamination and Maximum Germination Ratio for in Vitro Cotton (Gossypium hirsutum L.) Culture. Journal of Plant and Animal Sciences, 26, 868-873.

[12] Birecikli, A.H., Akbas, F. (2018). Effect of Auxin and Cytokinins on Micropropagation and Rooting of in vitro Shoot Tips of Safflower (Carthamus tinctorius L.) cv. “Balci”. Yüzüncü Yil Üniversitesi Journal of Agricultural Sciences, 28, 438-443.

[13] Tezcan, E. and Atıc1, O.G. (2016) Development of a New Technology for Delignification Process. PhD Thesis, Istanbul Technical University, Istanbul.

[14] Song, H., Ko, K., Oh, L. and Lee, B. (2006) Fabrication of Silver Nanoparticles and Their Antimicrobial Mechanisms. European Cells \& Materials, 11, Article No. 58.

[15] Turkish Public Health Institution (2015) Working Procedures and Principles of Biocidal Product Analysis Laboratories. T.C. Ministry of Health, Istanbul,Turkey.

[16] Ministry of Agriculture and Forestry (2010) TS EN 1276. Kimyasal dezenfektanlar ve antiseptikler-gıda sanayi, ev ve kuruluşlarda kullanılan kimyasal dezenfektanlar ve antiseptiklerin bakterisidal aktivitelerinin degerlendirilmesi için nicel süspansiyon deneyi-deney yöntemi ve özellikler. Turkish Standardization Institute, Ankara.

[17] Ministry of Agriculture and Forestry (2016) TS EN 13727+A2. Kimyasal dezenfektanlar ve antiseptikler-nicel suspansiyon deneyi-Tibbi alanda bakteri oldurme etkinliğinin degerlendirilmesi için-Deney yöntemi ve gerekler. Turkish Standardization Institute, Ankara.

[18] Moreira, C.F., Cassini-Vieira, P., da Silva, M.F. and Barcelos, L. (2015) Skin Wound Healing Model-Excisional Wounding and Assessment of Lesion Area. Bio-Protocol, 5, Article No. e1661. https://doi.org/10.21769/BioProtoc.1661

[19] Sutton, S. (2006) Measurement of Cell Concentration in Suspension by Optical Density. Pharmaceutical Microbiology Forum Newsletter, 12, 3-13.

[20] Orlikowska, T.K. and Dyer, W.E. (1993) In Vitro Regeneration and Multiplication 
of Safflower (Carthamus tinctorius L.). Plant Science, 93, 151-157. https://doi.org/10.1016/0168-9452(93)90044-Z

[21] Sánchez, E., Rivas Morales, C., Castillo, S., Leos-Rivas, C., Garcia-Becerra, L. And Ortiz Martinez, D.M. (2016) Antibacterial and Antibiofilm Activity of Methanolic Plant Extracts against Nosocomial Microorganisms. Evidence-Based Complementary and Alternative Medicine, 2016, Article ID: 1572697. https://doi.org/10.1155/2016/1572697

[22] Baba, A., Hasezawa, S. and Syōno, K. (1986) Cultivation of Rice Protoplasts and Their Transformation Mediated by Agrobacterium Spheroplasts. Plant and Cell Physiology, 27, 463-471. https://doi.org/10.1093/oxfordjournals.pcp.a077122

[23] Lussi, A. (1996) Autoclave. U.S. Patent No. 5535141.

[24] Thorpe, T.A. (1990) The Current Status of Plant Tissue Culture. Developments in Crop Science, 19, 1-33. https://doi.org/10.1016/B978-0-444-88883-9.50005-4

[25] Vasil, I.K. and Thorpe, T.A. (eds.) (1994) Plant Cell and Tissue Culture. Kluwer Academic, Dordrecht. https://doi.org/10.1007/978-94-017-2681-8

[26] Debergh, P.C. and Zimmerman, R.H. (Eds.) (1991) Micropropagatio/1. Kluwer Academic, Dordrecht.

[27] Gomi, M., Osaki, Y., Mori, M. and Sakagami, Y. (2012) Synergistic Bactericidal Effects of a Sublethal Concentration of Didecyldimethylammonium Chloride (DDAC) and Low Concentrations of Nonionic Surfactants against Staphylococcus aureus. Biocontrol Science, 17, 175-181. https://doi.org/10.4265/bio.17.175

[28] National Center for Biotechnology Information (2016) Didecyldimethylammonium Chloride. Household Products Database. US Department of Health and Human Services, Washington DC. 